\title{
Direct Synthesis of Lead-Hexaferrite Particles by Mist Pyrolysis
}

\author{
Y. IKEDA ${ }^{1}$, C. HARA ${ }^{1}$, T. FUJII', M. SATO ${ }^{2}$, and M. INOUE ${ }^{3}$
}

1) Department of Electrical and Electronic Engineering, Toyohashi University of Technology,
$1-1$ Hibari-ga-oka, Tempaku-cho, Toyohashi, Aichi 441, Japan
2) Honda Electronics Co., Ltd, 20 Oiwa-Cho, Toyohashi, Aichi $441-31$, Japan
3) Research Institute of Electrical Communication, Tohoku University,
2-1-1 Katahira, Sendai, Miyagi 980-77, Japan

Abstract- Lead-hexaferrite $\left(\mathrm{PbFe}_{12} \mathrm{O}_{19}\right.$, shortly $\left.\mathrm{PbM}\right)$ fine particles ranging from 0.038 to $0.6 \mu \mathrm{m}$ in diameter, were synthesized by mist pyrolysis. Mist was generated by an ultrasonic nebulizer operated at $f=2.6 \mathrm{MHz}$ from an aqueous solution of lead (II) nitrate and iron (III) nitrate dissolved in distilled water. Single phase $\mathrm{PbM}$ particles were directly obtained from the solution with the molar ratio( $\mathrm{Pb}) /(\mathrm{Fe})=$ $0.13 \sim 0.23$ of the solution, which is slightly high $\mathrm{Pb}$ concentration of the stoichiometric $\mathrm{PbM}$ composition (i.e. $(\mathrm{Pb}) /(\mathrm{Fe})=0.083$ ), after the mist passed through an electric furnace kept typically at $800^{\circ} \mathrm{C}$. The particle shape was apparently sphere, but they were the agglomeration of finer $\mathrm{PbM}$ particles of $0.01 \mu \mathrm{m}$ in diameter. The magnetic properties at room temperature are: $\sigma_{\mathrm{s}}$ (saturation moment) $=$ $56 \mathrm{emu} / \mathrm{g}, \mathrm{H}_{C}$ (coercivity) $=4 \sim 5 \mathrm{kOe}$, and $(\mathrm{BH})_{\text {maxx }}=0.7 \sim 0.9 \mathrm{M} \mathrm{G} \cdot \mathrm{Oe}$, which are the same magnitudes as in the reported values of $\mathrm{PbM}$. Monocrystalline $\mathrm{PbM}$ particles were obtained by annealing amorphous particles at $1000^{\circ} \mathrm{C}$ in a short duration $(\sim 5$ min.) in air.

\section{INTRODUCTION}

Since ferromagnetic fine particles are very important for various industrial applications such as permanent magnets, magnetic recording media, ferrofluids, etc., high quality powders with a narrow size distribution are now very requested. Mist pyrolysis is a production method of fine ceramic particles with diameter less than micronmeter by decomposing and oxidizing aerosol containing metallic ions. However only several attempts to produce magnetic oxide powders by this method such as magnetite[1], barium hexaferrite[2], and yttrium-iron garnet[3] have been reported to date. It is the purpose of this paper that lead hexaferrite $\left(\mathrm{PbFe}_{12} \mathrm{O}_{19}\right.$, shortly $\left.\mathrm{PbM}\right)$ fine particles is directly synthesized by pyrolysis from aerosol of an aqueous solution of nitrates utilizing ultrasonic neblization.

\section{EXPERIMENTAL METHOD}

The experimental apparatus for particle fabrication is essentially the same as was used for YIG particles[3]. The starting material is aqueous solutions of lead (II) nitrate $\left[\mathrm{Pb}\left(\mathrm{NO}_{3}\right)_{2}\right]$ and iron (III) nitride $\left[\mathrm{Fe}\left(\mathrm{NO}_{3}\right)_{3} \cdot 9 \mathrm{H}_{2} \mathrm{O}\right]$, adding a small amount of nitric acid to dissolve the nitrates completely in distilled water. The metallic ion concentration in the solution, $\mathrm{Cn}=(\mathrm{Pb})+(\mathrm{Fe})$, was changed from 0,0001 to $1.0[\mathrm{~mol} / \mathrm{L}]$ and its molar ratio, $\mathrm{R}=(\mathrm{Pb}) /(\mathrm{Fe})$, was adjusted from 0.08 to 1.5 . The mist was generated by an ultrasonic neblizer operated at $\mathrm{f}=2.6 \mathrm{MHz}$ and was introduced into an upright-type electric furnace (the reaction tube is $1.1 \mathrm{~m}$ long) together with oxygen carrier gas (the flow rate: $1.5 \sim 3.0 \mathrm{~L} / \mathrm{min}$.). The decomposition temperature, $T_{F}$ was changed from 400 to $1100^{\circ} \mathrm{C}$. The produced particles were collected at a water-trap equipped at the outlet of the reaction tube and the crystallographic identification was carried out by X-ray diffraction(XRD) and electron beam diffraction(EBD) and the particle size was measured from electron microscope images. Magnetic properties were examined by VSM at room temperature.

\section{RESULTS}

\subsection{Calibration of Composition}

Fig.1 is the relationship between the molar ratio $R$ of the starting solution and that of the as-collected particles for the solution with $\mathrm{Cn}=0.05 \mathrm{~mol} / \mathrm{L}$, where the composition was determined by EDX. A systematic deviation of composition is found, indicating that the larger the ion mass, the smaller amount of ion is contained in the mist which is

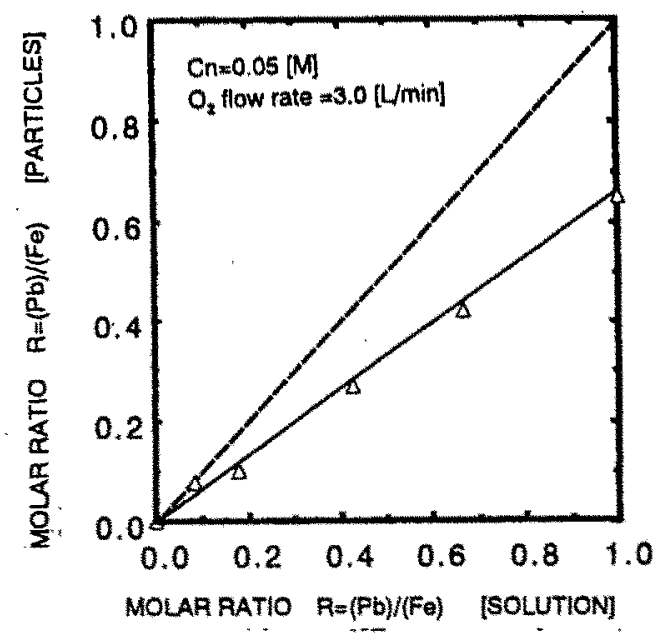

Fig.1 Relationship between the molar ratio $\mathrm{R}=(\mathrm{Pb}) / \mathrm{Fe})$ of starting solution and that of collected particles. 
presumably due to the gravitational force. This relation holds irrespective of the flow rate of carrier gas, the decomposition temperature and the ion concentration $\mathrm{Cn}$. Thus the particle composition can uniquely be determined once after such a calibration curve is taken unless the decomposition temperature exceeds above $900^{\circ} \mathrm{C}$.

\subsection{Preparation of PbM Particles}

We first examined the conditions for single phase PbM particle fabrication by changing $R$, where the decomposition temperature was $T_{F}=800^{\circ} \mathrm{C}$. The series of $\mathrm{XRD}$ patterns in Fig.2 is the results of as-collected particles with various $R$-values, where $X R D$ pattem of $P b M$ powder is shown at the bottom. It is found that single phase PbM particles ( $)$ were obtained in the range of $R=0.13 \sim 0.23$ [R of the stoichimetric $\mathrm{PbM}$ is 0.083 ]. For $\mathrm{R}<0.083$, hematite $\alpha-\mathrm{Fe}_{2} \mathrm{O}_{3}(\nabla)$ was predominantly formed in addition to $\mathrm{PbM}$, and for $\mathrm{R}=0.43$ and 0.67 , the diffraction lines from non-magnetic lead-ferrites of $\mathrm{PbFe}_{4} \mathrm{O}_{7}(O)$ and $\mathrm{Pb}_{2} \mathrm{Fe}_{2} \mathrm{O}_{6}(\diamond)$ are defected, respectively, Magnetic properties (saturation moment $\sigma_{\mathrm{S}}$ and coercivity ${ }_{1} \mathrm{H}_{\mathrm{C}}$ ) of these samples are plotted in Fig. 3, which is consistent with $X R D$ results in Fig.2. The maximum moment attained in our experiment is $\sigma_{\mathrm{S}}=56 \mathrm{emu} / \mathrm{g}$ at $\mathrm{R}=0.15$, which agrees with the reported value of $\mathrm{PbM}[4]$. All experiments hereafter were carried out for $R=0.15$. Next we examined the effect of decomposition temperature $T_{F}$ on magnetic properties. The result is shown in Fig.4. The maximum $\sigma_{S}$ was obtained at $T_{F}=800^{\circ} \mathrm{C}$ and with raising $T_{F}, \sigma_{S}$ is gradually decreased above $800^{\circ} \mathrm{C}$, while $\mathrm{H}_{\mathrm{C}}$ is monotono-

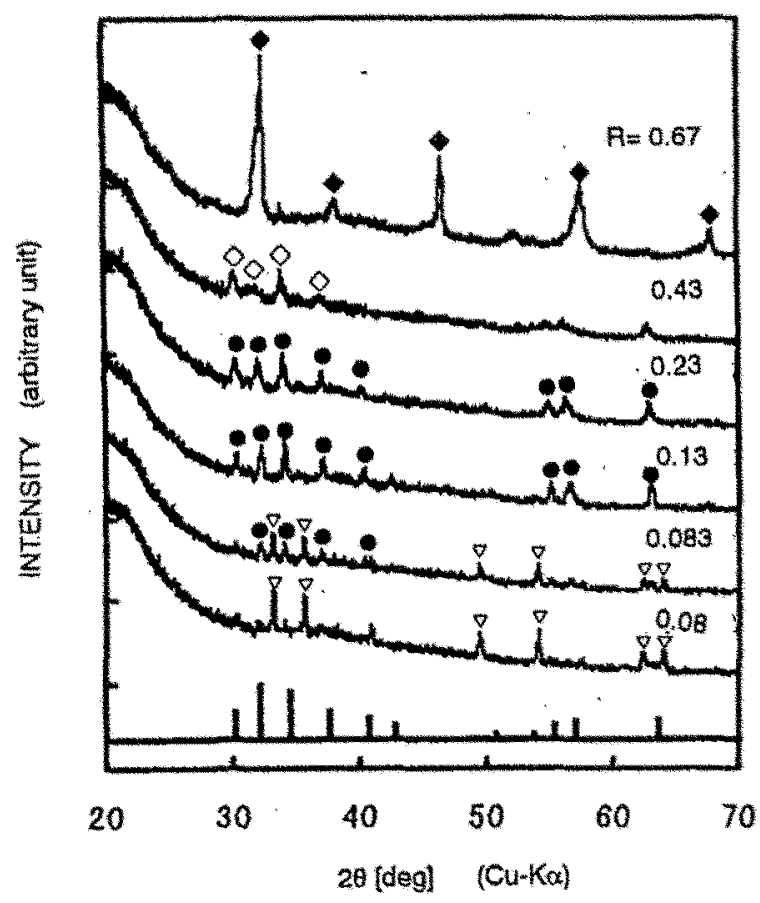

Fig.2 XRD patterns (Cu-Ka) of particles for various molar ratios, $R$. The marks in the figure refer to the text. nously increased. This is due to formation of hematite precipitates by evacuating $\mathrm{Pb}$ from particles. Hysteresis loops of two samples are shown in Fig.5. From the demagnetizing curve of these loops, we evaluated the maximum energy product $(\mathrm{BH})_{\max }$, being in the range of $0.7 \sim 0.9$ MGOe, which is reasonable value because our samples are assembly of isolating particles as shown in Figs.6 and 9.

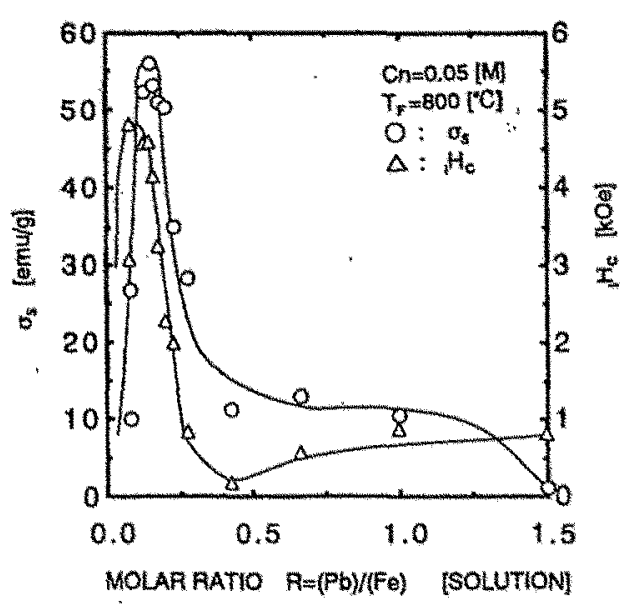

Fig.3 Saturation moment $\alpha_{s}$ and coercivity ${ }_{t} \mathrm{H}_{C}$ vs. the molar ratio of solution $R$.

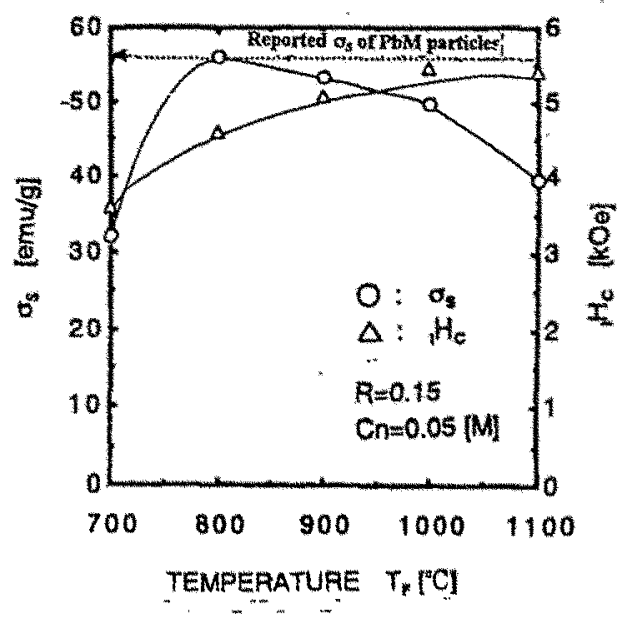

Fig.4 Dependence of decomposition temperature on magnetic properties $\left(\sigma_{s}\right.$ and $\left.H_{1}\right)$

\subsection{Particle Size and its Distribution}

Particle size and crystallinity were determined by electron microscope image and electron beam diffraction (EBD). Typical examples are shown in Figs.6(a) and (b), respectively, Particles are sphere, but seems to be porous, and agglomerating very fine particles, resulting in ring pattem in EBD. The apparent diameter of agglomerated particles is very sensitive to the ion concentration $\mathrm{Cn}$. The distribution of the apparent diameter is shown in Fig. 8 for two different $\mathrm{Cn}$ and its mean diameter is plotted against 


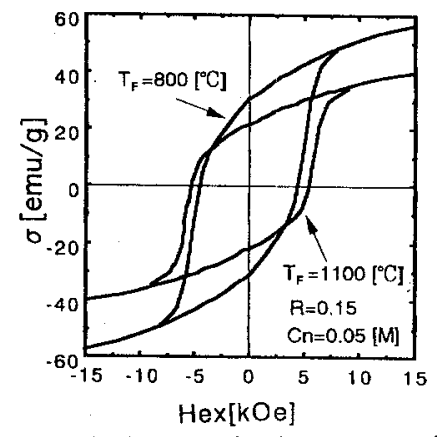

Fig.5 Two typical magnetization curves of particles

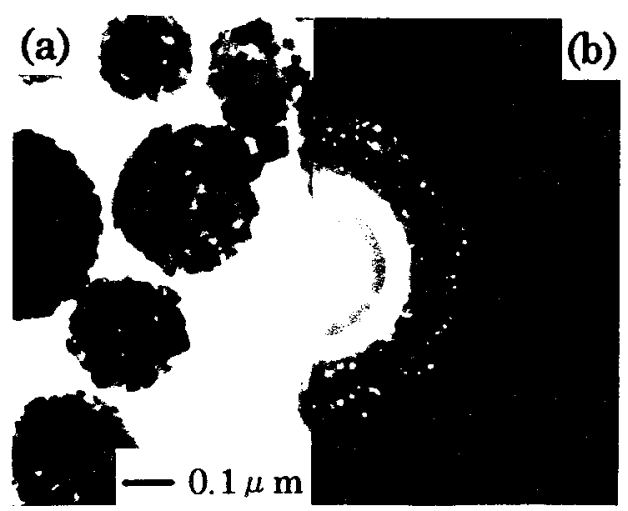

Fig.6 Electron microscope image (a) and electron diffraction pattern (b) of as-collected particles of as-collected particles

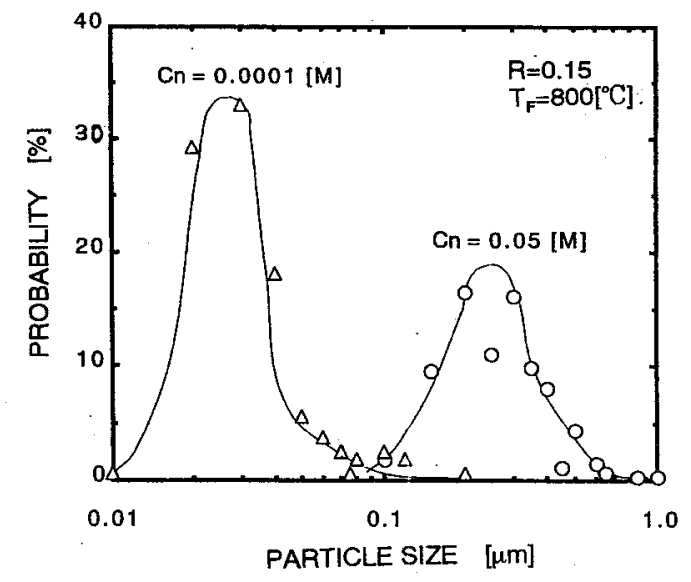

Fig.7 Particle size distribution for two different concentration of solution, $\mathrm{Cn}$.

Cn as shown in Fig. 8 together with the diameter of fine particles estimated from the (114) line width of XRD using Debye-Scherrer's formula, which is about $0.01 \mu \mathrm{m}$ almost independent of $\mathrm{Cn}$. The particle size falls on the single domain regime [the critical size is estimated to be $0.7 \mu \mathrm{m}$ ].

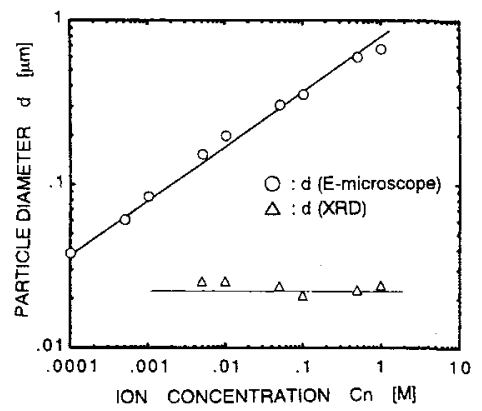

Fig. 8 Average particle diameter $(\mathrm{O})$ and particle size estimated from XRD (114) line width $(\triangle)$ vs. Ion concentration, $\mathrm{Cn}$.

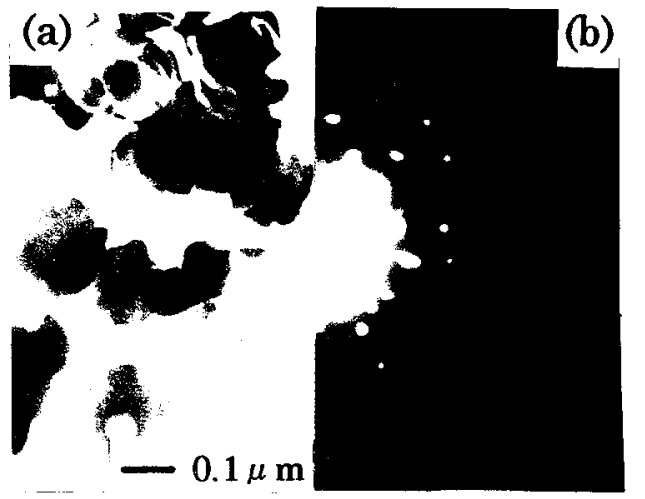

Fig.9 Electron microscope image (a) and electron diffraction pattern (b) of annealed sample $\left(1000^{\circ} \mathrm{C}\right.$ for $5 \mathrm{~min}$. in air).

\subsection{Post-annealing}

Since as-collected particles are found to be agglomerates of finer particles, we have examined annealing of the particles to obtain monocrystalline particles. Amorphous particles fabricated at $T_{\mathrm{F}}=600^{\circ} \mathrm{C}$ were crystallized by postannealing in air. Figs.9(a) and (b) are electron microscope image and EBD pattern of a sample annealed at $1000^{\circ} \mathrm{C}$ for 5 minutes, respectively. The porous structure vanishes and spot diffraction pattern with six-hold symmetry appears, indicating that each particle is nearly monocrystalline $\mathrm{PbM}$. $\sigma_{\mathrm{S}}$ of this sample is $56 \mathrm{emu} / \mathrm{g}$. Thus it is concluded that submicron size $\mathrm{PbM}$ particles are formed by mist pyrolysis after being post-annealed in air.

\section{.REFERENCES}

[1] M. Langlet, M. Labeau, B. Bochu, and J. C. Joubert, IEEE Trans. Magn., Vol.MAG-22, p.151, 1986.

[2] Z. X. Tang, S. Nafis, C. M. Sorensen, and G. C. Hajipanayis, IEEE Trans. Magn., Vol.MAG-25, p4236, 1989.

[3] K. Matsumoto, S. Sasaki, Y. Yamanobe, T. Fujii, K. Honda, and T. Miyamoto, J. Appl. Phys., Vol.70, p.5912, 1991.

[4] R.Pauthenet, and G.Rimet, Compt. Rend., Vol.249, p.656, 1959. 